\title{
Inisiasi Ekowisata Waduk Jatigede di Kecamatan Wado Kabupaten Sumedang, Provinsi Jawa Barat
}

\author{
[Ecotourism Initiation of Jatigede Reservoir in Wado District Sumedang \\ Regency, West Java]
}

\section{Widiya Asti}

\author{
Sekolah Tinggi Perikanan Jurusan Penyuluhan Perikanan Cikaret, \\ Jalan Cikaret Nomor 2, Kota Bogor 16001
}

Diterima: 13 September 2018; Disetujui: 12 November 2018

\begin{abstract}
Abstrak
Inisiasi ekowisata merupakan suatu langkah awal dalam pemanfaatan Waduk Jatigede sebagai lokasi wisata berbasis alam. Waduk Jatigede khususnya di Wilayah Kecamatan Wado dijadikan sebagai zona konservasi yang memiliki potensi untuk dijadikan sebagai lokasi ekowisata. Ekowisata Waduk Jatigede tentunya akan mendatangkan manfaat bagi masyarakat setempat. Tujuan dari kegiatan ini yaitu meningkatkan pengetahuan dan sikap masyarakat Kecamatan Wado mengenai pengelolaan sumberdaya perairan. Kegiatan ini dilakukan menggunakan metode diskusi atau Focus Group Discussion (FGD) dengan sasaran berbagai pihak pemangku kepentingan di Kecamatan Wado. Teknik pengambilan data yang digunakan yaitu berdasarkan skala Likert serta analisis data yang digunakan yaitu statistik deskriptif. Hasil dari kegiatan inisisasi ekowisata Waduk Jatigede adanya peningkatan pada aspek pengetahuan sebesar $107,0 \%$ dan aspek sikap tercatat memperoleh nilai 662 terhadap nilai tertinggi 750 yang menunjukkan bahwa wacana inisiasi terwujudnya kegiatan ekowisata di Waduk Jatigede memperoleh respon yang sangat tinggi. Berdasarkan hasil kegiatan ini masyarakat telah siap apabila pemerintah daerah telah menetapkan kebijakan tentang pengembangan wisata di Waduk Jatigede Kabupaten Sumedang, serta adanya saran-saran dalam pengelolaan Waduk Jatigede kepada Aparat Desa.
\end{abstract}

Kata kunci: ekowisata; focus group discussion; inisiasi; Waduk Jatigede

\section{Abstract}

Ecotourism initiation is an initial step in utilizing Jatigede Reservoir as a nature-based tourist location. Jatigede Reservoir, especially in the Wado Subdistrict Area, is used as a conservation zone that has the potential to be used as an ecotourism location. Ecotourism Jatigede Reservoir will certainly bring benefits to the local community. The purpose of this activity is to improve the knowledge and attitudes of the Wado District community regarding the management of water resources. This activity was carried out using a discussion or Focus Group Discussion (FGD) method with various stakeholders in Wado District. The data collection technique used is based on the Likert scales and the data analysis used is descriptive statistics. The results of the Jatigede Reservoir ecotourism initiation activity increased in the knowledge aspect by $107.0 \%$ and the attitude aspect was recorded to reach 662 against the highest value of 750; which indicated that initiating the realization of ecotourism activities in the Jatigede Reservoir recieved a very high response. Based on the results of this activity the community is ready if the local government has established a policy on the development of tourism in the Jatigede Reservoir in Sumedang Regency, as well as suggestions on the management of the Jatigede Reservoir to the Village Apparatus.

Keywords: ecotourism; focus group discussion; initiation; Jatigede Reservoir 


\section{PENDAHULUAN}

Indonesia memiliki sejumlah lokasi tujuan wisata alam yang sangat khas dan unik, khususnya wisata yang berhubungan dengan perairan. Areal wisata terkait wilayah perairan tawar, pada umumnya identik dengan upaya-upaya konservasi. Hal ini dimaksudkan agar ketersediaan air tawar dengan kualitas yang terjaga serta berkemampuan mendukung keanekaragaman hayati pada perairan untuk tetap lestari. Lokasi wisata perairan tawar yang terkenal di Indonesia, antara lain Danau Toba, Sungai Mahakam, atau Waduk Jatiluhur Selain itu, masih banyak potensi perairan tawar serupa yang belum tergali dengan optimal, satu diantaranya adalah Waduk Jatigede yang terletak di Kabupaten Sumedang, Provinsi Jawa Barat, yang masih terbilang baru, karena baru diresmikan pada tahun 2015.

Sebagaimana diketahui, bahwa waduk adalah genangan air yang dibentuk oleh buatan manusia. Ada beberapa definisi tentang waduk, antara lain menurut Notohadiprawiro (2006) dan Krisanti (2006) dalam Yuono (2012) ada-lah muka lahan untuk menampung air hujan secukupnya pada musim basah atau tempat menampung air yang umumnya dibentuk dari sungai atau rawa dengan tujuan tertentu. Waduk Ja-tigede ini, memiliki luas area sebesar 3.035,34 Ha. Pembentukkannya diawali dengan menggenangi lima Kecamatan yang ada di Kabupaten Sumedang de-ngan rincian sebagai berikut: Kecmatan Jatigede $760,55 \mathrm{Ha}$ (terdiri dari desa Ci-ranggem, Jemah, Mekarasih, Cije-ungjing dan Sukakersa); Kecamatan Ja-tinunggal 239,89 $\mathrm{Ha}$ (terdiri dari desa Pawenang dan Sirnasari); Kecamatan Wado 459,23 $\mathrm{Ha}$ (terdiri dari desa Wa-do, Cisurat dan Padajaya); Kecamatan Darmaraja seluas 1.575,67 Ha (terdiri dari desa Cibogo, Cipaku, Jattibungur, Karangpakuan, Leuwihideung, Pakua-lam, Sukamenak, Sukaratu, Tarunajaya dan Cikeusi); Kecamatan Cisitu 48.65 Ha (terdiri dari desa pajagan).

Pembangunan Waduk Jatigede memiliki manfaat langsung dan tidak langsung, namun manfaat yang paling utama dari kegiatan pembangunan waduk ini yakni sebagai air baku bagi daerah-daerah lain yakni Cirebon, Majalengka, dan Indramayu sehingga hal ini memberatkan kepada masyarakat Kabupaten Sumedang dan menimbulkan berbagai permasalahan baik dari segi ekonomi, sosial, dan budaya. Permasalahan yang paling memberatkan bagi masyarakat yakni masyarakat ter- 
dampak pembangunan waduk kehilangan tempat tinggal dan mata pencahariannya. Menanggapi permasalahan ini maka ditetapkan Peraturan Presiden Nomor 1 tahun 2015 tentang Penanganan Dampak Sosial Kemasyarakatan pada Pembangunan Waduk Jatigede dengan memberikan pesangon atau penggantian berupa uang dan tempat tinggal yang dibangun oleh pemerintah di daerah Kabupaten lain (Anonimus 2015). Sedangkan pada permasalahan masyarakat yang kehilangan pekerjaan atau mata pencaharian belum teratasi. Oleh karena itu perlu adanya pengembangan Sumber Daya Manusia (SDM) yang dilakukan oleh pemerintah dengan mengadakan pelatihan untuk meningkatkan keahlian masyarakat terdampak.

Zonasi kawasan perikanan di Waduk Jatigede diatur dalam Peraturan Daerah Kabupaten Sumedang Nomor 2 Tahun 2012 tentang Rencana Tata Ruang Wilayah Kabupaten Sumedang tertera pada Bab VIII pasal 49 yakni sebagai tempat penangkapan ikan, dan dilarang melakukan kegiatan perikanan Keramba Jaring Apung (KJA) (Anonimus 2012). Peraturan yang dibuat oleh pemerintah Kabupaten Sumedang dimaksudkan agar tidak mengulangi kesalahan yang sama pada pembangunan waduk sebelumnya yakni pencemaran air waduk. Selain itu Peraturan Daerah Pemerintah Kabupaten Sumedang No- mor 2 Tahun 2002 tentang Rencana Tata Ruang Wilayah Kabupaten Sume-dang tertera pada Bab V pasal 35 menjelaskan bahwa adanya rencana pe-ngembangan kawasan wisata Waduk Ja-tigede dengan maksud bahwa Waduk Jatigede akan dikembangkan sebagai lo-kasi wisata. Berdasarkan peta rencana pengembangan wisata Waduk Jatigede bahwa Kecamatan Wado pada wilayah Desa Wado dijadikan sebagai wilayah konservasi, hal ini berpotensi untuk dijadikan sebagai wilayah ekowisata.

Pada proses pengembangan ekowisata Waduk Jatigede tentunya membutuhkan waktu yang cukup panjang dan membutuhkan langkah awal atau inisiasi dalam memberikan kesadaran kepada masyarakat tentang adanya po-tensi Waduk Jatigede sebagai tempat wisata. Inisiasi berasal dari kata bahasa Latin, initium, yang berarti masuk atau permulaan, secara harafiah berarti masuk ke dalam. Inisiasi awal dapat diartikan sebagai langkah awal dalam pengembangan ekowisata Waduk Jatigede dengan melakukan kegiatan memberikan kesadaran pada masyarakat tentang pemanfaatan Waduk Jatigede. Ekowisata merupakan salah satu kegiatan pariwisata yang berwawasan lingkungan dengan mengutamakan aspek konservasi alam, aspek pemberdayaan sosial budaya ekonomi masyarakat lokal serta aspek pembelajaran dan pendi- 
dikan. Ekowisata dapat dilihat sebagai suatu konsep pengembangan pariwisata berkelanjutan yang bertujuan untuk mendukung upaya-upaya pelestarian lingkungan, juga meminimalisir dampak, menumbuhkan kesadaran lingkungan dan budaya, memberikan pengalaman positif pada turis maupun penerima, memberikan manfaat dan pemberdayaan masyarakat lokal (Satria Dias 2009; Hadi 2007 dalam Kurnianto 2008). Tujuan dari penelitian ini adalah untuk melihat sejauhmana kesadaran masyarakat dalam kegiatan ini-siasi ekowisata perairan Waduk Jati-gede.

\section{BAHAN DAN METODE}

Penelitian dilakukan pada bulan Februari sampai dengan bulan April 2018 di Kecamatan Wado Kabupaten
Sumedang. Pengambilan data menggunakan alat instrumen berdasarkan skala Likert. Menurut Krisyanto (2006) dalam Janti (2014), skala Likert merupakan skala yang digunakan untuk mengukur sikap, pendapat, dan persepsi seseorang atau kelompok orang tentang kejadian atau gejala sosial. Menurut Likert (1932) dalam Budiaji (2013) skala Likert menggunakan beberapa butir pertanyaan untuk mengukur perilaku individu dengan merespon lima titik pilih-an pada setiap butir pertanyaan, yaitu: sangat setuju, setuju, tidak memutuskan, tidak setuju dan sangat tidak setuju. Lokasi penelitian dilihat pada Gambar 1.

Pada penelitian ini, nilai pada pernyataan skala Likert yang digunakan adalah: $1=$ sangat tidak setuju, $2=$ tidak setuju, $3=$ ragu-ragu, $4=$ setuju; dan $5=$

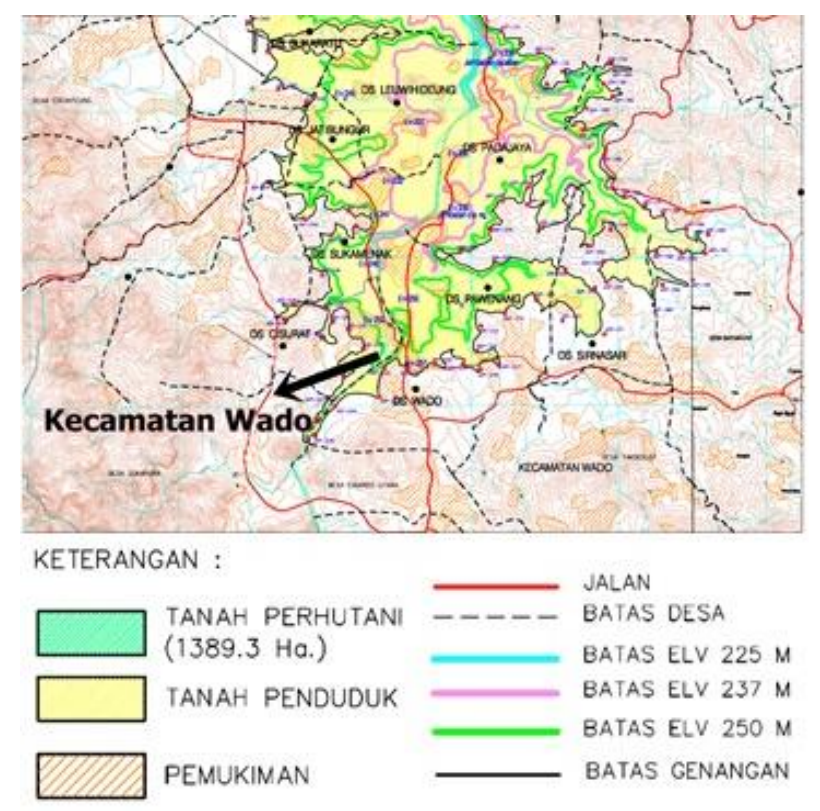

Gambar 1. Lokasi titik penelitian Kecamatan Wado (Sumber. Satker Jatigede 2017) 
sangat setuju. Pada setiap lima titik pilihan nilai skala likert disiapkan 10 pertanyaan, sehingga jumlah pertanyaan sebanyak 50 yang ditujukan kepada setiap responden. Pilihan metode sampling responden yang digunakan adalah dengan metoda purposive sampling, analisis data yang digunakan yakni statistik deskriptif.

\section{HASIL DAN PEMBAHASAN}

Hasil

Peningkatan pengetahuan dan sikap masyarakat terhadap pengelolaan sumberdaya perairan sebagai langkah awal atau inisiasi awal ekowisata Wa-duk Jatigede telah dilakukan pada sa-saran yang berjumlah 15 orang di Desa Wado Kecamatan Wado. Sasaran terdiri dari pihak-pihak terkait yang dapat mendukung kegiatan ekowisata yaitu Nelayan (satu orang); Petani (dua orang); Warga (enam orang); Karang

Tabel 1. Evaluasi hasil aspek pengetahuan inisiasi ekowisata Waduk Jatigede

\begin{tabular}{llllll}
\hline No & Nama Responden & $\begin{array}{c}\text { Evaluasi } \\
\text { Awal }\end{array}$ & $\begin{array}{c}\text { Evaluasi } \\
\text { Akhir }\end{array}$ & $\begin{array}{c}\text { Perubahan } \\
\text { dari total } \\
\text { soal =10 }\end{array}$ & $\begin{array}{c}\text { Peningkatan } \\
\text { (\%) }\end{array}$ \\
\hline 1 & Andi S & 5 & 10 & 5 & 100 \\
2 & Anam & 4 & 9 & 5 & 90 \\
3 & Suhendra & 5 & 9 & 4 & 80 \\
4 & Tibiin & 2 & 8 & 6 & 300 \\
5 & Roni Irawan & 5 & 10 & 5 & 100 \\
6 & Suparman & 5 & 10 & 5 & 100 \\
7 & Eme & 3 & 6 & 3 & 100 \\
8 & Edi R & 6 & 10 & 4 & 67 \\
9 & Engkus & 4 & 8 & 4 & 100 \\
10 & Wawan & 4 & 9 & 5 & 125 \\
11 & Dodi Heris & 4 & 10 & 6 & 150 \\
12 & Risnandar & 6 & 8 & 2 & 33 \\
13 & Idid & 4 & 5 & 1 & 25 \\
14 & Rahmat & 4 & 8 & 4 & 100 \\
15 & Deris & 4 & 8 & 4 & 100 \\
\hline Total & 65 & 128 & 63 & 1605 \\
\hline Rata-rata & 4,3 & 8,5 & 4,2 & 107 \\
\hline Presentase & $4,3 \%$ & $8,5 \%$ & $4,2 \%$ & \\
\hline 6 & Data & & & \\
\hline
\end{tabular}

Sumber: data primer, hasil olahan 2018 
Taruna (dua orang); Kelompok Masyarakat Pengawas/ Pokmaswas (satu orang); Lembaga Permusyawaratan Masyarakat Desa (satu orang); dan Aparat Desa (dua orang). Sasaran yang diambil merupakan sampel dari populasi yang memiliki karakteristik yang dapat dianggap mewakili populasi (Arikunto 2009). Adapun hasil dari evaluasi aspek pengetahuan pada kegiatan inisiasi eko- wisata Waduk Jatigede dapat dilihat pada Tabel 1. Sedangkan Evaluasi hasil aspek sikap inisiasi ekowisata Waduk Jatigede dengan nilai terendah dan nilai teringgi, dapat lihat pada Tabel 2. Serta garis kontinum aspek sikap inisiasi ekowisata Waduk Jatigede yang dapat dilihat pada Gambar 2. Tampilan keindahan alam Waduk Jatigede saat matahari terbit, dapat dilihat pada Gambar 3.

Tabel 2. Evaluasi aspek sikap inisiasi ekowisata Waduk Jatigede dengan skala Likert

\begin{tabular}{lllll}
\hline No & Nama Responden & $\begin{array}{c}\text { Nilai } \\
\text { Terendah }\end{array}$ & $\begin{array}{c}\text { Nilai } \\
\text { Tertinggi }\end{array}$ & $\begin{array}{c}\text { Nilai } \\
\text { Perolehan }\end{array}$ \\
\hline 1 & Andi S & 10 & 50 & 47 \\
2 & Anam & 10 & 50 & 42 \\
3 & Suhendra & 10 & 50 & 48 \\
4 & Tibiin & 10 & 50 & 40 \\
5 & Roni Irawan & 10 & 50 & 48 \\
6 & Suparman & 10 & 50 & 43 \\
7 & Eme & 10 & 50 & 48 \\
8 & Edi R & 10 & 50 & 42 \\
9 & Engkus & 10 & 50 & 45 \\
10 & Wawan & 10 & 50 & 46 \\
11 & Dodi Heris & 10 & 50 & 44 \\
12 & Risnandar & 10 & 50 & 44 \\
13 & Idid & 10 & 50 & 41 \\
14 & Rahmat & 10 & 50 & 44 \\
15 & Deris & 10 & 50 & 40 \\
\hline Total & 150 & 750 & 662 \\
\hline
\end{tabular}

Sumber: data primer, hasil olahan 2018

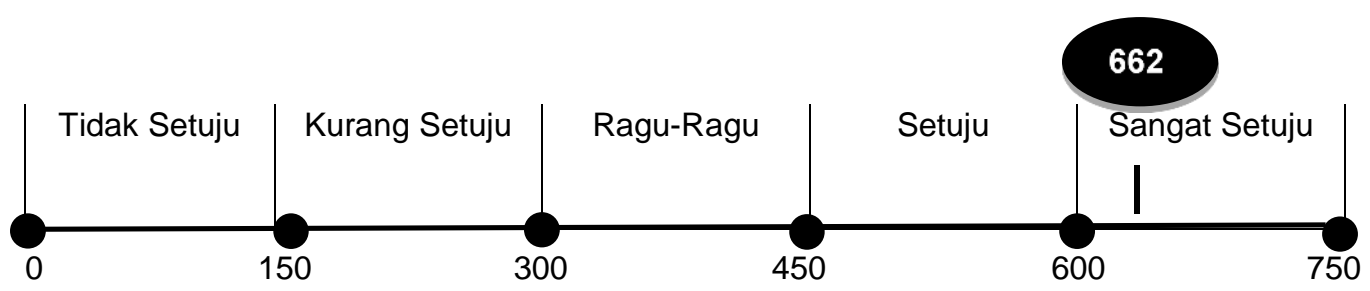

Gambar 2. Garis kontinum aspek sikap inisiasi ekowisata Waduk Jatigede 


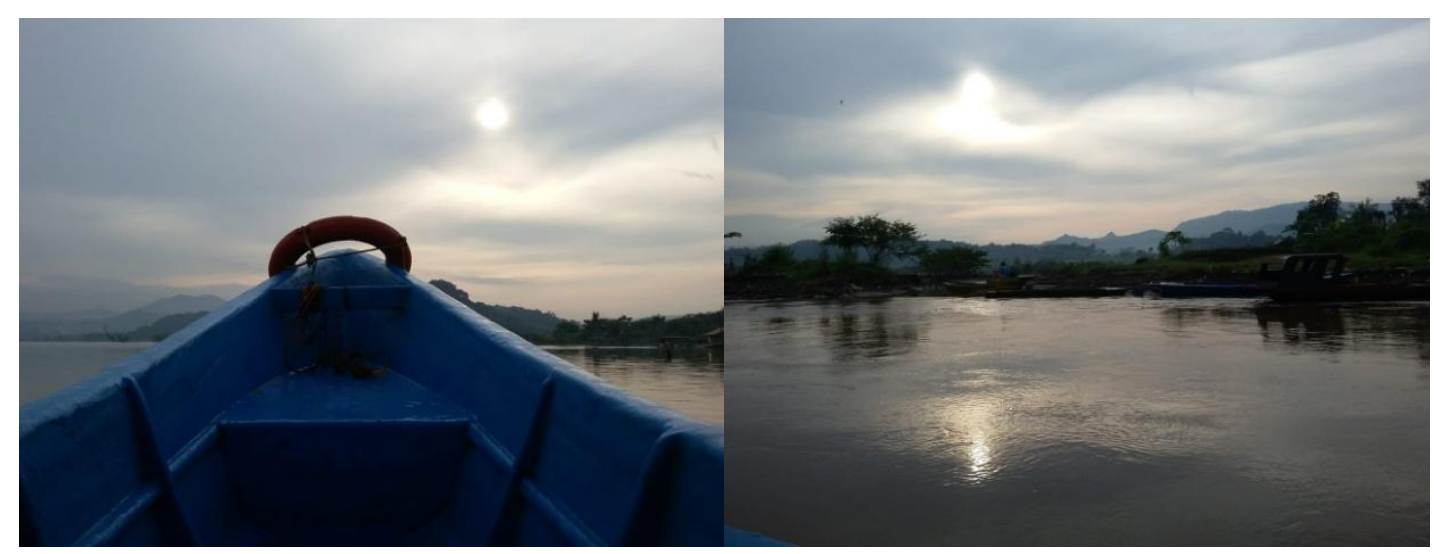

Gambar 2. Tampilan keindahan alam Waduk Jatigede, saat matahari terbit (sumber dokumentasi: Asti 2018)

\section{Pembahasan}

Berdasarkan penilaian evaluasi aspek pengetahuan pada sasaran melalui kegiatan sosialisasi inisiasi ekowisata Waduk Jatigede sebelum melakukan penyuluhan memiliki nilai rata-rata yakni sebesar 4,3 dan terjadi peningkatan pada sasaran setelah dilakukan kegiatan penyuluhan yakni sebesar 8,5. Sehingga terjadi perubahan rata-rata sebesar $42 \%$ dan peningkatan sebesar $107 \%$; sebagaimana terlihat pada Tabel 1. Perubahan pada aspek pengetahuan ini, lebih karena terinformasikannya Peraturan Daerah Pemerintah Kabupaten Sumedang Nomor 2 Tahun 2002 tentang Rencana Tata Ruang Wilayah Kabupaten Sumedang. Hal ini terkait berdasarkan peta rencana pengembangan wisata Waduk Jatigede bahwa Kecamatan Wado pada wilayah Desa Wado dijadikan sebagai wilayah konservasi, hal ini berpotensi untuk dijadikan sebagai wilayah ekowisata. Dari perolehan hasil pengetahuan responden tentang inisiasi pengembangan ekowisata Waduk Jatigede, sebesar 8,5 dari nilai tertinggi 10, memberikan gambaran bahwa sebagian besar masya-rakat terdampak pembagunan Waduk Jatigede menyadari perlunya diwujud-kan kegiatan ekowisiata Waduk Jati-gede untuk menambah penghasilan masyarakat terdampak tersebut. Berbagai hasil kajian tentang inisiasi terwujudnya suatu kegiatan ekowisata perairan, cukup banyak ditulis untuk dijadikan acuan sebagai salah satu upaya penambahan penghasilan masyarakat setempat dengan mengoptimalkan kein-dahan/ kelebihan sumber daya alam yang dimiliki; antara lain upaya pe-ngembangan ekowisata Situ Ciledug dan Situ Cigintung di Kota Tangerang Selatan; juga pengembangan ekowisata berbasis perikanan di Kecamatan Gla-gah dan Licin Kabupaten 
Banyuwangi, Jawa Timur (Fauzi 2016; Widodo dkk 2018).

Pada hasil evaluasi aspek sikap pada kegiatan menjaring pendapat masyarakat tentang inisiasi ekowisata Waduk Jatigede, diperoleh total skor pada sejumlah 662 dengan nilai rata-rata 44; sebagaimana terlihat pada Tabel 2. Untuk memperoleh nilai selang pada skala Likert, diolah skor tertinggi dari penilaian adalah 750 diperoleh dari $(5 \mathrm{x}$ $10 \times 15$ responden) dan nilai terendah adalah 150 dari ( $1 \times 10 \times 15$ responden). Nilai 662 terhadap nilai tertinggi 750 pada Garis Kontinum Gambar 2., menunjukkan bahwa wacana inisiasi terwujudnya kegiatan ekowisata di Waduk Jatigede memperoleh respon yang sangat tinggi. Dari hasil wawancara langsung dengan para nelayan penangkap ikan di Waduk Jatigede, usaha penangkapan tersebut tidak bisa diandalkan untuk dijadikan mata pencaharian. Hal ini disebabkan sedikitnya ikan yang tertangkap. Kondisi menurunnya jumlah tangkapan ikan, khusus ikan asli Waduk Jatigede, sejalan dengan hasil penelitian Asti dkk. (2018) yang menyatakan bahwa dari 15 species ikan asli yang ditemukan di Waduk Jatigede pada tahun 2017, hanya tertinggal 11 species ikan asli yang tertangkap.

Peluang untuk mewujudkan kegiatan ekowisata Waduk Jatigede, juga ditunjang dengan adanya Kelompok Pengawas Masyarakat/Pokwasmas, serta Karang Taruna yang sudah mulai mempersiapkan diri untuk berlatih bersama secara mandiri sebagai pemandu wisata. Materi-materi untuk bahan pemandu wisata, didapatkan pengurus Karang Taruna dari cerita para orang tua mereka tentang sejarah pembendungan Waduk Jatigede. Kelompok nelayan yang tersisa juga sudah mulai berbenah untuk merapikan perahunya yang nantinya akan dilengkapi dengan peralatan lifejacket, pelampung; untuk memberi rasa aman kepada para calon wisatawan lokal, yang akan menjadi tujuan target utama adalah anak-anak sekolah yang ingin menjadikan ekowisata ini sebagai wisata pendidikan; maupun wisatawan dari seputar Provinsi Jawa Barat.

Beberapa catatan kajian yang menyatakan upaya pengelolaan yang optimal suatu kawasan wisata, memerlukan informasi mengenai karakteristik dan potensi dari perairan seperti situ serta adanya strategi pengelolaan wisata perairan (Fauzy 2016). Tampaknya masyarakat di sekitar Waduk Jatigede, sudah bersikap mulai memikirkan perlu adanya sarana penunjang pariwisata, seperti akomodasi, kegiatan kuliner oleh kelompok ibu-ibu, kebersihan lokasi serta promosi wisata membuat potensi Waduk Jatigede dapat terus berkembang sebagai kawasan ekowi- 
sata. Selain itu, pada beberapa kegiatan ekowisata perairan, juga dapat digandeng dengan program Culture Based Fisheries (CBF) dengan melakukan restocking ikan secara rutin dengan ikanikan asli Waduk Jatigede atau dengan ikan konsumsi yang tidak berpotensi sebagai ikan asing invasif. Catatan keberhasilan CBF di Waduk Jatiluhur dengan melakukan penebaran ikan bandeng pada tahun 2008; sampai saat ini masih dinilai dapat meningkatkan pendapatan nelayan; sekaligus mengurangi dampak penurunan kualitas air karena tingginya kegiatan Karamba Jaring Apung. Khusus tentang penebaran ikan bandeng ini, kajian beberapa peneliti memperlihatkan bahwa dari segi kebijakan, penebaran ikan bandeng di Waduk Jatiluhur merupakan pilihan kebijakan yang terukur; dengan usulan agar memperkuat kelembagaan masyarakat (kelompok nelayan/UKB atau kelompok masyarakat pengawas/Pokmaswas) untuk penataan dari kegiatan hulu sampai ke hilir (Koeshendrajana dkk. 2011).

Menurut Kartamihardja (2008) kebijakan penebaran ikan bandeng di Waduk Ir. H. Juanda yang juga dikenal dengan nama Waduk Jatiluhur pada tahun 2008, diawali dengan pemikiran bahwa Waduk Ir. H. Juanda ini sudah tergolong waduk dengan kondisi ekosistem perairan yang subur sampai sangat subur dengan kandungan sum- berdaya makanan alami yang relatif tinggi pada zona limnetik. Karenanya menebar jenis ikan yang dapat memanfaatkan biomasa fotoplankton secara efisien, akan merupakan pilihan terbaik. Satu diantaranya adalah ikan bandeng; walaupun nilai ekonomisnya sangat tinggi, akan tetapi benih bandeng perlu ditebar berulang. Untuk mengatasi masalah penebaran berulang ini, disarankan menebar jenis ikan ringo (Thynnichthys thynnoides) atau ikan motan (Thynnichthys polylepis) sebagaimana dilakukan di Waduk Koto Panjang, Ri-au; dan termasuk jenis ikan ekonomis penting. Kajian Burnawi (2011) di Wa-duk Koto Panjang mempertegas kondisi bahwa ikan motan mampu berkembang-biak di waduk; dengan demikian tidak diperlukan penebaran berulang seperti penebaran bandeng di Waduk Juanda. Lebih lanjut Burnawi (2011) mengata-kan bahwa ikan motan dengan kisaran ukuran panjang 18-26 cm, bobot ikan 69-162 g, bobot gonad 6,65-17,56 gram mempunyai kisaran fekunditas 25.360.000-61.198.000 butir telur. Hal ini mengindikasikan bahwa kemampuan ikan motan berkembangbiak di Waduk Koto Panjang, sangat tinggi. Ber-dasarkan masukan dari dua peneliti di-atas, dapat disarankan agar pemilihan jenis benih tebar untuk Waduk Jatigede dapat menggunakan tahapan yang dila-kukan di Waduk Juanda-Jawa 
Barat dan Waduk Koto Panjang-Riau. Sebagai do-rongan motivasi guna meningkakan mi-nat para nelayan sebagai masyarakat terdampak pembangunan Waduk Jati-gede menjalankan progran CBF, tercatat harga jual ikan bandeng Rp 23.000 perkilogram ukuran 3-4 ekor setiap kilogram di Sumedang (data primer, Maret 2018); dan harga jual ikan motan karena memiliki cita rasa daging yang lezat terutama setelah diolah menjadi ikan salai, harga ikan motan salai menjadi $\mathrm{Rp}$ 75.000,- per-kilogram (Burnawi 2011)

Selain CBF, kajian Fauzan (2016) jug menambahkan untuk mengembangkan kegiatan ekowisata di Kecamatan Samboja, Kabupaten Kukar, Provinsi Kalimantan Utara; diusulkan juga untuk mengembangkan konsep ekowisata berbasis masyarakat atau Community based Ecotourism (CBE). Wisata berbasis masyarakat ini memberikan peran yang lebih kepada masyarakat lokal untuk bertanggung jawab pada konservasi lingkungan serta ikut bersama memajukan usaha-usaha pemberdayaan ekonomi masyarakat lokal; dan wisata yang menghargai budaya lokal.

\section{SIMPULAN DAN SARAN}

Adanya peningkatan kesadaran masyarakat dalam kegiatan inisiasi ekowisata Waduk Jatigede terlihat adanya diskusi partisipatif dengan sasaran. Hal ini dapat dilihat dari perolehan nilai pada aspek pengetahuan sebesar 8,5 dari nilai tertinggi 10; Sehingga terjadi peru-bahan rata-rata sebesar $42 \%$ dan pe-ningkatan sebesar 107\%. Hal ini mem-berikan gambaran bahwa sebagian besar masyarakat terdampak pembangunan Waduk Jatigede menyadari perlunya diwujudkan kegiatan ekowisiata Waduk Jatigede untuk menambah penghasilan masyarakat terdampak tersebut

Pada aspek sikap tercatat memperoleh nilai 662 terhadap nilai tertinggi 750 yang menunjukkan bahwa wacana inisiasi terwujudnya kegiatan ekowisata di Waduk Jatigede memperoleh respon yang sangat tinggi. Masyarakat lebih sadar dalam menjaga dan mengelola Waduk Jatigede dan masyarakat beserta pemerintah setempat telah siap apabila terdapat kebijakan yang pasti dalam pembangunan ekowisata di Waduk Jatigede.

Adapun saran dalam kegiatan ini yaitu perlu adanya kerjasama antara pemerintah Kabupaten Garut dengan pemerintah Kabupaten Sumedang untuk menangani permasalahan sampah yang masuk ke dalam area bendungan Waduk Jatigede khususnya wilayah Kecamatan Wado, penetapan kebijakan secara resmi bahwa Waduk dapat dijadikan sebagai lokasi wisata, dan menerapkan program Culture Based Fisheries (CBF) 
dengan melakukan restocking ikan secara rutin: serta mendorong partisipasi masyarakat dalam bentuk program Community based Ecotourism (CBE).

\section{PERSANTUNAN}

Ucapan terima kasih disampaikan kepada Ketua Jurusan Penyuluhan Perikanan, Sekolah Tinggi Perikanan, yang telah memberikan kesempatan melakukan kegiatan penelitian bersamaan dengan kegiatan Praktek Akhir Taruna tingkat Utama/IV Jurusan Penyuluhan Perikanan, Sekolah Tinggi Perikanan; kepada Pimpinan Dinas Perikanan dan Peternakan Kabupaten Sumedang Jawa Barat untuk dukungan data sekunder yang diberikan; Camat Kecamatan Wado dan Kepala Desa Wado; serta Camat Kecamatan Darmaraja dan Kepala Desa Sukaratu, Kepala Desa Pakualam atas fasilitas perijinan melakukan penelitian.

\section{DAFTAR PUSTAKA}

Anonimous. 2012. Peraturan Daerah Nomor 2 Tahun 2012 tentang rencana tata ruang Wilayah Kabupaten Sumedang tahun 20112031. Sumedang: Bupati Sumedang.

Anonimous. 2015. Peraturan Presiden Nomor 1 tahun 2015 tentang Penanganan Dampak Sosial Kemasyarakatan Pembangunan Waduk Jatigede.
Asti W, LS Syafei, Sujono, D Sudinno. 2018. Iktiofauna di Waduk Jatigede Kabupaten Sumedang Provinsi Jawa Barat. Disampaikan dalam Seminar Nasional Ikan ke10 di LIPI-Cibinong Jawa Barat, 10 Mei 2018. 15 hal.

Arikunto S. 2010. Prosedur Penelitian Suatu Pendekatan Praktek. Edisi Revisi 2010. Penerbit Rineka Cipta, Jakarta.

Budiaji W. 2013. Skala pengukuran dan jumlah responden skala likert. Jurnal IImu Pertanian dan Perikanan, 2(2): 127-135

Burnawi. 2011. Pengamatan fekunditas ikan motan (Thynnichthys polylepsis) hasil tangkapan nelayan dari Waduk Koto Panjang, Provinsi Riau. Buletin Teknik Litkayasa Sumber Daya Penang-kapan, 9(1): $1-5$

Fauzan. 2016. Kajian pengembangan ekowisata di kawasan wisata alam di Kecamatan Samboja, Kabupaten Kukar. Jurnal Eksis, 12(1): 3214-3345

Fauzi F. 2016. Analisis potensi wisata Situ Ciledug dan Situ Gintung di Kota Tangerang Selatan. Jurnal Pro-Life , 3(2): Juli 2016

Janti S. 2014. Analisis validitas dan realibilitas dengan skala Likert terhadap pengembangan $\mathrm{S} 1 / \mathrm{T} 1$ 
dalam penelitian pengambilan keputusan penerapan strategik planning pada industri garmen. Prosiding Seminar Nasional Aplikasi Sains dan Teknologi (SNAST) 2014. Yogyakarta, 15 November 2014. A: $155-160$

Kartamihardja ES. 2008. Perubahan komposisi komunitas ikan dan faktor-faktor penting yang mempengaruhi selama empat puluh tahun umur Waduk Juanda. Jurnal Iktologi Indonesia, 8(2): 67-78

Koeshendrajana S, T Apriliani, M Firdaus, Z Nasution, A Nurfiarini. 2011. Penebaran ikan bandeng di Waduk Jatiluhur: analisis dampak dan kebijakan pengembangan. Jurnal Kebijakan Sosial Ekonomi Kelautan dan Perikanan, 1(1): 1-17 Kurnianto IR, 2008. Pengembangan ekowisata (ecotourism) di kawasan Waduk Cacaban, Kabupaten Tegal. Tesis. Program Studi Ma-gister Ilmu Lingkungan. Program Pasca Sarjana, Universitas Dipo-negoro. 180 hal.

Satria, Dias. 2009. Strategi pengembangan ekowisata berbasis ekowisata lokal dalam rangka program pengentasan kemiskinan di wilayah Kabupaten Malang. Jur-nal Ekowisata. Vol 12: 3 p.
Satker. 2017. Satuan Kerja: SNVT Pembangunan Waduk Jatigede. Satminkal: Direktorat Jenderal Sumber Daya Air. Provinsi Jawa Barat. https://eproc.pu.go.id

Widodo MS, B Kusuma, F Fariedah. 2018. Kajian potensi ekowisata berbasis perikanan di Kecamatan Glagah Licin, Kabupaten Banyuwangi, Jawa Timur. Journal of Fisheries and Marine Research, 2(3): 160-165

Yuono T. 2012. Evaluasi kinerja sistem irigasi Waduk Cengklik. Jurnal Teknik Sipil dan Arsitektur, 12(6): $1-18$ 